\title{
Abusive head trauma: two cases and mini-review of the current literature
}

\author{
Sitkı Tiplamaz ${ }^{1 \oplus}$, Abdülvehhap Beygirci ${ }^{2 \oplus}$, Murat Nihat Arslan ${ }^{3 \oplus}$, \\ Mehmet Akif İnanıc1 ${ }^{4 \oplus}$ \\ ${ }^{1}$ The Council of Forensic Medicine, Gümüşhane Directorate Branch of Forensic Medicine, Gümüşhane; ${ }^{2}$ Department of Pediatric, \\ University of Health Science Kanuni Sultan Suleyman Research and Training Hospital, İstanbul; ${ }^{3}$ Morgue Department, The Council of \\ Forensic Medicine, İstanbul; ${ }^{4}$ Department of Forensic Medicine, Marmara University Faculty of Medicine, İstanbul, Turkey.
}

\begin{abstract}
Background. Abusive head trauma (AHT) is the leading cause of fatal head injuries and are responsible for more than half of serious or fatal traumatic brain injury cases in children younger than 2 years of age. Long-term outcomes of AHT are death, spastic hemiplegia or quadriplegia, intractable epilepsy, microcephaly with corticosubcortical atrophy, visual impairment, language disorder and cognitive, behavioral and sleep disorders.

Cases. Herein we present two cases of AHT (7-month-old boy, 7-month-old girl) according to forensic analysis, and discuss them in light of the current literature and share our experience. Inconsistency between the presenting history and the clinical findings were typical in both cases; follow-up histories and detailed workup revealed the diagnosis of AHT. The first case was deceased; the second case was discharged with neurological deficits.
\end{abstract}

Conclusion. A multidisciplinary approach is critical for the prevention, diagnosis and treatment of AHT.

Key words: shaken baby syndrome, retinal hemorrhage, subdural hemorrhage, forensic.

Abusive head trauma (AHT) is the leading cause of fatal head injuries and responsible for more than half of serious or fatal traumatic brain injury cases in children younger than 2 years of age. ${ }^{1}$ According to Chevignard and Lind ${ }^{2}$, long-term outcomes of AHT are death (20-25\%), spastic hemiplegia or quadriplegia (15-64\%), intractable epilepsy (11-32\%), microcephaly with cortico-subcortical atrophy (61-100\%), visual impairment (18-48\%), language disorder (37-64\%) and cognitive, behavioral and sleep disorders $(23-59 \%)$. Prevention of AHT is of utmost importance for saving children from mortality and morbidity. The estimated lifetime cost of 4,824 cases at ages 0-4 years in 2010 was $\$ 13,5$ billion in the USA. ${ }^{3}$

Sitk1 Tiplamaz

tiplamaz@yahoo.com

Received 18th February 2019, accepted 19th January 2020.
In 1946, Caffey ${ }^{4}$ first documented six children with chronic subdural hematoma and fractures of long bones in his study. After that other authors mentioned this phenomenon..$^{5-7}$ In 1962, Kempe et al. ${ }^{8}$ named it as "battered-child syndrome". In 1971, Guthkelch ${ }^{9}$ suggested that subdural hematoma (SDH) in infants could be created by whiplash forces which tear the bridging veins. He made this suggestion based on Ommaya's study in 1968 on primates using rotational movement of the head on the neck to produce concussion and SDH. ${ }^{10}$ In 1972, Caffey ${ }^{11}$ coined the term "whiplash shaken infant syndrome" defined by infants with $\mathrm{SDH}$ and/or subarachnoid hemorrhage (SAH), retinal hemorrhages $(\mathrm{RH})$, with little or no external marks of trauma to the head. In 1987, Duhaime et al. ${ }^{12}$ hypothesized that based on clinical, pathological data and biomechanical models, the rotational acceleration/deceleration whiplash injuries do not provide enough force to account for the severe injuries of these 
children and that in severe cases blunt trauma must be involved. After this article, the term shaken infant/shaken impact emerged. There are still debates over whether shaking alone or shaking with blunt trauma is required. ${ }^{13-15}$ The etiology of injury is multifactorial (shaking, shaking and impact, impact alone, etc.) so that the current best and most inclusive term is AHT, as recommended by the American Academy of Pediatrics.

The aim of this study was to share our experience about how to diagnose and handle AHT which is rarely diagnosed, and review the literature. An informed consent was received from the legal guardians. This study was carried out in concordance with international ethical standards and the World Health Organisation Helsinki Declaration. It was approved by The Presidency of The Council of Forensic Medicine Education and Scientific Research Board (Approval No:21589509/2018/709) and the local ethics committee of the Medical Faculty of Marmara University (Protocol No:1016).

\section{Case Reports}

\section{Case 1}

A 7-month-old male infant was brought to the emergency department with complaints of inability to breathe and cyanosis of the lips. At the first interview, the mother stated that "After I had fed the baby, I left the room. Ten minutes later I found him in a color of purple, lying face down". On the presentation to the hospital, the infant had tachycardia and tachypnea. Glasgow Coma Score (GCS) was 7, his body temperature was $36.7{ }^{\circ} \mathrm{C}$. He was intubated and was referred to the intensive care unit. His blood and cerebrospinal fluid cultures were negative for microbiological agents. Complete blood count, electrolytes, coagulation tests, liver and kidney function tests were also normal. Cranial computerized tomography (CT) depicted subdural hemorrhage on falx cerebri and surface of bilateral cerebellar hemispheres, predominantly on the left side. Brain magnetic resonance (MR) imaging scan verified the CT findings. The neurosurgeon opted conservative treatment approach with anti-edema and anti-seizure medication. When the retina was examined, bilateral intra and pre-retinal hemorrhages were found. Both transfontanel and abdominal ultrasound (US) findings were normal for any other traumatic injuries. Also, the full body skeletal survey was negative.

The pregnancy period of the mother was uncomplicated and the infant was born by vaginal delivery at term. The birth weight of the infant was 2,875 g; there was no ante-, peri-, or post-natal medical problems.

Then the infant was directed to the Child Protection Unit in the hospital for the evaluation of suspected child abuse. In several interviews at the Child Protection Unit; the mother reported that she was 31-year-old and had two marriages. Both of these marriages ended in divorce. She had four children from these marriages. Two of the children were from the first husband. The parental rights of those two children were with the biological father. The infant was born as the fourth child of the mother from her second marriage. The parents had divorced and the children were living with their mother and the mother's new partner. The partner was an employee of a cargo company and was rarely at home, he didn't care about the children. The mother was emotionally and economically dependent on the partner. The mother didn't have alcohol or drug abuse. According to the history obtained from the mother, on that day, she fed the child and put him on her shoulders. While she was trying to hold the child, he fell down to the ground. Two to 3 days later, she realized the deviation of the eyes and loss of consciousness of the child. She decided to bring the child to the emergency unit. These statements of the mother were inconsistent with her first interview. The follow-up histories of the mother, presence of bilateral retinal and subdural hemorrhages and no other explanations for presented findings were diagnosed as AHT by the council. Then the case was reported to Directorate of Family and Social Policies Ministry and the public 
prosecutor. After 20 days in the hospital, the infant was taken to state care by social workers. When he was being discharged from the hospital, as a consequence of global paralysis, he got stage 2 spasticity in the upper extremities, stage 3 spasticity in the lower right extremity and global blindness.

Two months after discharge, he died and an autopsy was performed posthumous, his brain was atrophic and the cause of death was pneumonia. Figure 1 shows the severity of brain atrophy.

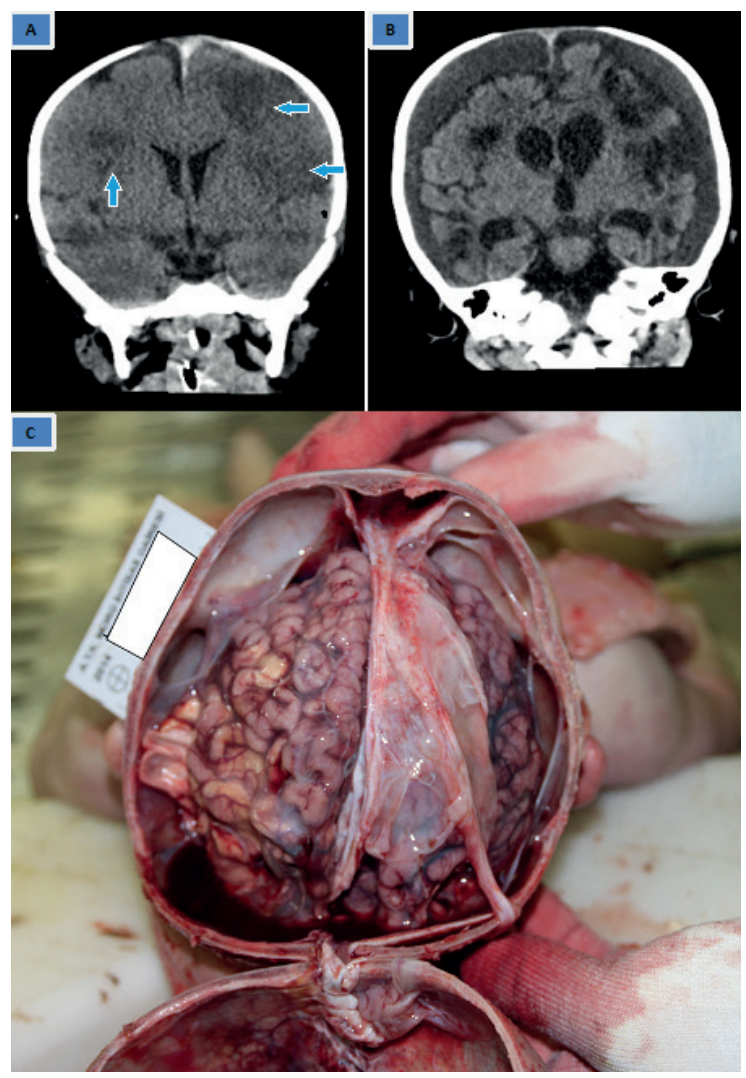

Fig. 1. Generalized cerebral atrophy progressions due to abusive head trauma of case 1: A) a coronal non-contrast computerized tomography (CT image), 4 days after trauma, revealed subacute hypodense lesions (arrows indicate lesions), B) a coronal noncontrast CT image, 68 days after trauma (obtained from Marmara University Hospital with permission), revealed generalized cerebral atrophy and chronic subdural effusion, C) autopsy image, 112 days after abusive head trauma (obtained from The Council of Forensic Medicine with permission) showed generalized cerebral atrophy.

\section{Case 2}

A 7-month-old female infant was brought to the emergency room with complaints of vomiting, seizures lasting 10-15 minutes and altered mental status. The infant was referred to our hospital for further evaluation and treatment. At the first interview, the mother stated that "the baby had weird movements. Then I shook her by holding her feet in order to bring her consciousness back and to stop the movements. But that attempt was not successful and my sister-in-law hit the infant's back."

The infant was presented as being conscious, hypotonic, lethargic and pale. Her GSC was 11. She was unable to hold her head in an upright position. The neurological exam showed that she had a right-sided hemiparalysis. Her cardiovascular and respiratory systems were normal. Cranial CT depicted subdural hemorrhage. The infant was referred to the intensive care unit to treat the recurrent seizures and cranial hemorrhage. Her blood and cerebrospinal fluid cultures were negative for microbiological agents. Complete blood count, electrolytes, coagulation tests, liver and kidney function tests were also normal. The neurosurgeon opted for conservative treatment approach with anti-edema and anti-seizure medication. When the retina was examined, bilateral pre-retinal hemorrhages were found. Brain MR angiography and venography were normal. Abdominal US was also normal for any other traumatic injuries. Full body skeletal survey was negative. The mother's pregnancy was desired and uncomplicated. The infant was born at the gestational age of 38 weeks with a birth weight of 2,200 g.

Then the infant was directed to the Child Protection Unit in the hospital for the evaluation of suspected child abuse. In the interviews in the Child Protection Unit; the mother stated that she was 39-year-old, had three children, and was not working at that time. The father was 35-year-old and he was working in a bar. The mother explained that the day had been very strenuous because the infant had cried 
for long periods of time. While she was trying to put the infant to sleep, she started doing some spasmodic movements. Then the mother grabbed her by her feet and shook her several times. She described her shaking as mild. Psychiatric examination of the mother revealed that she had not shown any psychopathological mistreatment of her child.

The follow-up histories of the mother, presence of pre-retinal and subdural hemorrhages and no other explanations for presented findings were diagnosed as AHT by the Council. Then the case was reported to Directorate of Family and Social Policies Ministry. After spending 25 days at the hospital, her condition became more stable, seizures were under control and she was discharged from the hospital. During the medical treatment procedures, social investigation report about the family revealed that the family provided basic needs for children. The neighbors of the family stated that they had not witnessed any violence inside the family or against the children. Social services decided to support and educate the parents about child development and how to overcome difficult situations. And also social services provided them with advisory assistance about parental skills. The infant was left in her parents' care and the parents obligated to bring her to pediatric neurology and physical medicine and rehabilitation clinics for followup examinations. No legal action was taken against the family.

Table I shows the clinical short summary of the cases.

\section{Discussion}

The diagnosis of AHT is made like any other medical diagnosis, by getting all the information acquired via clinical history, physical examination, and laboratory and imaging. Inconsistency between the presenting history and the clinical findings is an important diagnostic tool for child maltreatment including AHT so detailed history including follow-up histories are vital for the accuracy of diagnosis. ${ }^{16,17}$ In both of our cases, there was an inconsistency between presenting histories and follow-up histories. The most common history is a minor fall (less than $1.5 \mathrm{~m}) .{ }^{18}$ As in case 1 , the mother dropped the infant from her shoulder. But hitherto literature shows us that death from minor falls is extremely rare, and the majority of these have minor traumatic lesions or no lesion. ${ }^{19,20}$ There is no pathognomonic finding for AHT. Compilation of injuries most often include SDH, complex retinal hemorrhage

Table I. Clinical short summary of cases.

\begin{tabular}{|c|c|c|}
\hline Clinical features & Case 1 & Case 2 \\
\hline Gender & Male & Female \\
\hline Age & 7 months & 7 months \\
\hline Presenting history & Infant lying face down & Infant had weird movements \\
\hline Follow-up history & $\begin{array}{l}\text { Mother dropped infant from shoulder to } \\
\text { ground }\end{array}$ & $\begin{array}{l}\text { Infant cried all day. Mother partly admitted } \\
\text { to shaking her baby }\end{array}$ \\
\hline $\begin{array}{l}\text { Cranial } \\
\text { computerized } \\
\text { tomography images }\end{array}$ & $\begin{array}{l}\text { Subdural haemorrhage on falx cerebri and } \\
\text { surface of bilateral cerebellar hemispheres, } \\
\text { predominantly on the left side }\end{array}$ & Subdural haemorrhage \\
\hline Retinal examination & Bilateral intra and pre-retinal haemorrhage & Bilateral pre-retinal haemorrhage \\
\hline $\begin{array}{l}\text { Social condition of } \\
\text { the family }\end{array}$ & $\begin{array}{l}\text { Mother had complex psychosocial issues } \\
\text { (divorced, male-dependent low economic } \\
\text { income) }\end{array}$ & $\begin{array}{l}\text { Exhausted mother spent all her time with } \\
\text { infant and house work. }\end{array}$ \\
\hline Result & $\begin{array}{l}\text { Infant was taken from mother's care, but } \\
\text { died after two months. }\end{array}$ & $\begin{array}{l}\text { Social services supported family regarding } \\
\text { child development and parental skills. } \\
\text { Infant was followed by schedule at hospital }\end{array}$ \\
\hline
\end{tabular}


and/or retinoschisis, rib, metaphyseal or other fractures, and soft-tissue injury leads to the diagnosis. Findings inconsistent with the provided history of trauma and the severity and age of the findings provide clues to the diagnosis. Subdural hemorrhage is the most common finding in AHT, is most commonly parafalcine in location and is seen in 90-95\% of fatal cases and in 40-55\% of living patients where it is imaged by either CT or MRI ${ }^{12,19,21,22}$, but brain parenchymal injury is the most important cause of morbidity and mortality. ${ }^{23}$ In both of our cases, the babies had subdural hemorrhages and in case 1, SDH was on falx cerebri and surface of bilateral cerebellar hemispheres. A review by Maguire ${ }^{24}$ mentioned that any combination of 3 or more of the apnea, retinal hemorrhage, rib, skull, and long-bone fractures; seizures; and head and/or neck bruising yielded an Odds ratio of $>100$ (positive predictive value for AHT $>85 \%$ ).

Palusci and Covington ${ }^{25}$ identified that a trigger to AHT's death was crying (20\%), disobedience $(6 \%)$, domestic arguments $(5 \%)$, toilet training $(4 \%)$ and feeding problems $(3 \%)$. In case 2 , the mother was exposed to crying for a long period of time.

Clinicians should perform a detailed examination of external lesions. Lesions to the head and face have been associated with AHT, and patterns of injury consistent with grabbing, choking and blunt trauma should be sought. Also, clinicians should keep in mind that the absence of external lesion is common. ${ }^{26}$

The skeletal survey according to guidelines should be performed for all children that are suspicious for AHT, especially those younger than 2 years. ${ }^{27}$ Suspicion of AHT that warrants full-body imaging, does not have a similar diagnosis procedure with low-risk blunt head trauma. ${ }^{28}$ In both of our cases, the skeletal surveys were found to be normal. If the child is brought to a hospital in acutely ill condition with severe neurologic symptoms, it is recommended to start imaging with unenhanced CT with 3-D reformatted images of the calvarium ${ }^{29}$ followed by a full multisequence MRI of the brain and the cervical, thoracic and lumbar spine as soon as possible. MRI is more sensitive than CT in showing parenchymal lesions and early diagnosis of brain parenchymal injury is very important for preventing morbidity and mortality so children who are in a good condition neurologically, can be imaged with MR first. ${ }^{30}$ Also, MRI is better in characterizing extra-axial bleeds and defining cerebral contusion, laceration and other parenchymal brain injuries than CT.

Younger children get more severe cognitive and motor function deficits than will older children. ${ }^{31}$ Also, young infants have increased the risk for upper cervical injury (generally soft tissue or ligamentous). ${ }^{32}$

Ocular findings in AHT can be orbital and lid ecchymosis, subconjunctival hemorrhage, anisocoria, and disconjugate eye movements and retinal hemorrhages. In the absence of head trauma findings, retinal hemorrhage is more specific for AHT. ${ }^{33}$ Retinal hemorrhages $(\mathrm{RH})$ are very common findings in AHT and are found in $84 \%$ of cases. ${ }^{34}$ The $\mathrm{RHs}$ which are mostly associated with AHT tend to be very multiple in the layers of the retina and which can extend to the ora serrata. ${ }^{35,36}$ The RHs are generally bilateral but in some cases appear in only one eye. Early detection of retinal hemorrhages is very important because they can fade rapidly. Generally, intraretinal hemorrhages fade rapidly but preretinal hemorrhages could persist for many weeks. It is recommended that eye examination should be done as early as possible, preferably within 24$48 \mathrm{hrs} .{ }^{37}$ In case 1 , the infant had bilateral retinal hemorrhages, in case 2 , the infant had bilateral pre-retinal hemorrhages.

Differential diagnosis should be done by clinicians. Accidental head trauma, medical or surgical manipulations, pre- and peri-natal conditions, birth trauma, metabolic disorders, clotting disorders, tumors, autoimmune disorders, infectious diseases, long-term shunting of hydrocephalus, and miscellaneous 
other conditions need to be distinguished from AHT. It is compulsory to consider other causes and to examine all aspects of the history, physical examination, radiological imaging, and laboratory studies to exclude other causes and the question to be answered is "Is there any cause other than AHT to explain the child's medical findings and condition?".

When accidental head trauma and AHT are compared: 1- skull fractures are equally common, but the complex skull fractures are more common in AHT; 2- epidural hematomas are more common in accidental trauma; 3subdural hematomas are far more common in AHT; and 4- subarachnoid, intraparenchymal and intraventricular hemorrhage are equally common in both AHT and accidental trauma. ${ }^{14,38-41}$

Prevention should be the main aim of dealing with AHT. Healthcare providers who work in pediatric and emergency departments must be educated and trained about identifying parents at high risk of child abuse and the parents should be taught how to deal with a crying baby and the danger of shaking or blunt impact on an infant with an undeveloped brain. Diagnosis of AHT is also important in countries like Turkey where it is rarely diagnosed. Due to the fact that diagnosis of AHT is not just a constellation of medical symptoms or finding, a multidisciplinary approach is needed. This multidisciplinary team should include pediatricians, neurosurgeons, radiologists, ophthalmologists, forensic medicine experts, social workers, and other health care professionals.

\section{REFERENCES}

1. Keenan HT. A population-based study of inflicted traumatic brain injury in young children. JAMA 2003; 290: 621-626.

2. Chevignard MP, Lind K. Long-term outcome of abusive head trauma. Pediatr Radiol 2014; 44(Suppl 4): S548-S558.

3. Miller TR, Steinbeigle R, Lawrence BA, et al. Lifetime cost of abusive head trauma at ages 0-4, USA. Prev Sci 2018: 19; 695-704.
4. Caffey J. Multiple fractures in the long bones of infants suffering from chronic subdural hematoma. Am J Roentgenol Radium Ther 1946; 56: 163-173.

5. Lis EF, Frauenberger GS. Multiple fractures associated with subdural hematoma in infancy. Pediatrics 1950; 6: 890-892.

6. Silverman FN. The roentgen manifestations of unrecognized skeletal trauma in infants. Am J Roentgenol Radium Ther Nucl Med 1953; 69: 413427.

7. Woolley PV, Evans WA. Significance of skeletal lesions in infants resembling those of traumatic origin. JAMA 1955; 158: 539-543.

8. Kempe $\mathrm{CH}$, Silverman FN, Steele BF, Droegemmueller W, Silver HK. The battered-child syndrome. JAMA 1962; 181: 17-24.

9. Guthkelch AN. Infantile subdural haematoma and its relationship to whiplash injuries. Br Med J 1971; 2: $430-431$.

10. Ommaya AK, Faas F, Yarnell P. Whiplash injury and brain damage: an experimental study. JAMA 1968; 204: 285-289.

11. Caffey J. On the theory and practice of shaking infants. Its potential residual effects of permanent brain damage and mental retardation. Am J Dis Child 1972; 124: 161-169.

12. Duhaime AC, Gennarelli TA, Thibault LE, Bruce DA, Margulies SS, Wiser R. The shaken baby syndrome. A clinical, pathological, and biomechanical study. J Neurosurg 1987; 66: 409-415.

13. Starling SP, Patel S, Burke BL, Sirotnak AP, Stronks $\mathrm{S}$, Rosquist P. Analysis of perpetrator admissions to inflicted traumatic brain injury in children. Arch Pediatr Adolesc Med 2004; 158: 454-458.

14. Vinchon M, de Foort-Dhellemmes S, Desurmont M, Delestret I. Confessed abuse versus witnessed accidents in infants: comparison of clinical, radiological, and ophthalmological data in corroborated cases. Child's Nerv Syst 2010; 26: 637645.

15. Adamsbaum C, Grabar S, Mejean N, Rey-Salmon C. Abusive head trauma: judicial admissions highlight violent and repetitive shaking. Pediatrics 2010; 126: 546-555.

16. Palusci VJ. Risk factors and services for child maltreatment among infants and young children. Child Youth Serv Rev 2011; 33: 1374-1382.

17. Hennes H, Kini N, Palusci VJ. Chapter three: The epidemiology, clinical characteristics and public health implications of shaken baby syndrome. J Aggress Maltreatment Trauma 2001; 5: 19-40. 
18. Feldman KW, Bethel R, Shugerman RP, Grossman DC, Grady MS, Ellenbogen RG. The cause of infant and toddler subdural hemorrhage: a prospective study. Pediatrics 2001; 108: 636-646.

19. Gilles EE, Nelson MD. Cerebral complications of nonaccidental head injury in childhood. Pediatr Neurol 1998; 19: 119-128.

20. Chadwick DL, Bertocci G, Castillo E, et al. Annual risk of death resulting from short falls among young children: less than 1 in 1 million. Pediatrics 2008; 121: 1213-1224.

21. Case ME, Graham MA, Handy TC, Jentzen JM, Monteleone JA; National Association of Medical Examiners Ad Hoc Committee on Shaken Baby Syndrome. Position paper on fatal abusive head injuries in infants and young children. Am J Forensic Med Pathol 2001; 22: 112-122.

22. Bradford R, Choudhary AK, Dias MS. Serial neuroimaging in infants with abusive head trauma: timing abusive injuries. J Neurosurg Pediatr 2013; 12: 110-119.

23. Choudhary AK, Servaes S, Slovis TL, et al. Consensus statement on abusive head trauma in infants and young children. Pediatr Radiol 2018; 48: 1048-1065.

24. Maguire SA, Kemp AM, Lumb RC, Farewell DM. Estimating the probability of abusive head trauma: a pooled analysis. Pediatrics 2011; 128: e550-e564.

25. Palusci VJ, Covington TM. Child maltreatment deaths in the U.S. national child death review case reporting system. Child Abuse Negl 2014; 38: 25-36.

26. Gill JR, Goldfeder LB, Armbrustmacher V, Coleman A, Mena H, Hirsch CS. Fatal head injury in children younger than 2 years in New York City and an overview of the shaken baby syndrome. Arch Pathol Lab Med 2009; 133: 619-627.

27. Expert Panel on Pediatric Imaging:, WoottonGorges SL, Soares BP, Alazraki AL, et al; ACR appropriateness criteria ${ }^{\circledR}$ suspected physical abusechild. J Am Coll Radiol 2017; 14(5S): S338-S349.

28. Magana JN, Kuppermann N. The PECARN TBI rules do not apply to abusive head trauma. Acad Emerg Med 2017; 24: 382-384.

29. Choudhary AK, Jha B, Boal DK, Dias M. Occipital sutures and its variations: the value of $3 \mathrm{D}-\mathrm{CT}$ and how to differentiate it from fractures using 3D-CT? Surg Radiol Anat 2010; 32: 807-816.
30. Girard N, Brunel H, Dory-Lautrec P, Chabrol B. Neuroimaging differential diagnoses to abusive head trauma. Pediatr Radiol 2016; 46: 603-614.

31. Agran PF, Anderson C, Winn D, Trent R, WaltonHaynes L, Thayer S. Rates of pediatric injuries by 3-month intervals for children 0 to 3 years of age. Pediatrics 2003; 111(6 Pt 1): e683-e692.

32. Choudhary AK, Ishak R, Zacharia TT, Dias MS. Imaging of spinal injury in abusive head trauma: a retrospective study. Pediatr Radiol 2014; 44: 11301140.

33. Levin AV. Retinal hemorrhage in abusive head trauma. Pediatrics 2010; 126: 961-970.

34. Kivlin JD. A 12-year ophthalmologic experience with the shaken baby syndrome at a regional children's hospital. Trans Am Ophthalmol Soc 1999; 97: 545581.

35. Christian CW, Taylor AA, Hertle RW, Duhaime AC. Retinal hemorrhages caused by accidental household trauma. J Pediatr 1999; 135: 125-127.

36. Levin AV. Ophthalmology of shaken baby syndrome. Neurosurg Clin N Am 2002; 13: 201-211.

37. Binenbaum G, Chen W, Huang J, Ying G, Forbes BJ. The natural history of retinal hemorrhage in pediatric head trauma. J Am Assoc Pediatr Ophthalmol Strabismus 2016; 20: 131-135.

38. Duhaime AC, Alario AJ, Lewander WJ, et al Head injury in very young children: mechanisms, injury types, and ophthalmologic findings in 100 hospitalized patients younger than 2 years of age. Pediatrics 1992; 90 (2 Pt 1): 179-185.

39. Kelly P, John S, Vincent AL, Reed P. Abusive head trauma and accidental head injury: a 20-year comparative study of referrals to a hospital child protection team. Arch Dis Child 2015; 100: 1123-1130.

40. Ewing-Cobbs L, Kramer L, Prasad M, et al Neuroimaging, physical, and developmental findings after inflicted and noninflicted traumatic brain injury in young children. Pediatrics 1998; 102 (2 Pt 1): 300-307.

41. Myhre M, Grogaard JB, Dyb GA, Sandvik L, Nordhov M. Traumatic head injury in infants and toddlers. Acta Paediatr 2007; 96: 1159-1163. 